\title{
DIE DOLEANSIE, VRIJE UNIVERSITEIT EN DIE POTCHEFSTROOMSE UNIVERSITEIT VIR CHRISTELIKE HOERR ONDERWYS
}

Ur. C. J. Malan.

Dit is presies 100 jaar gelede dat die Doleansie tot stand gekom het. Omdat die Vrije Universiteit baie nou met hierdie beweging saamgaan en die PU vir CHO op sy beurt, weer noue verwantskap toon met die gebeure rondom die Doleansie - daarom enkele gedagtes rondom hierdie gebeurtenis.

Ná die Afskeiding van 1834 het daar in die Hervormde kerk nog baie lidmate oorgebly wat ontevrede was met die leer en kerk regering van die kerk, maar wat ook besware teen die Afskeiding gehad het. Hulle uitgangspunt was dat lidmate nie met die kerk moet breek nie maar die kerk van binne moes hervorm.

\section{Beweging vir kerkherstel}

Vanaf 1841 kry ons dan ook daadwerklike pogings om die kerk vry te maak van "Het Algemeen Reglement" van koning Willem I waardeur die gereformeerde Dordtse Kerkorde finaal gelikwideer is en die kerkregering 'n hiërargiese struktuur verkry het (d'Assonville, $1986: 2$ ). Herhaaldelik word in die jare 1842,1843 en 1848 vertoë gerig vir die handhawing van die suiwere Skriftuurlike leer, die gesag van God se Woord en die gereformeerde belydenis. In die hele kerkverband was daar beroering oor die Godonterende en kerkverwoestende bedryf van baie vrysinnige predikante (Honders, 1964: 8. 42).

Een van die groot kampvegters vir die Gereformeerde Belydenis in die Hervormde kerk was Groen van Prinsterer. Reeds in 1842 dien hy, saam met ses ander Hagenaars, 'n beswaarskrif by die Sinode in met die titel Adres aan de Algemeene Synode der Nederlandsche Hervormde Kerk over de Formulieren, de Academische Opleiding der predikanten, het Onderwijs en het Kerkbestuur. In hierdie adres vra die beswaardes dat die Sinode dit onomwonde moet stel dat die Heilige Skrif die enigste kenbron en onfeilbare toetssteen van die geloof is; dat hulle die antichristelike leer van 3 hoogleraars van die Groningerrigting as teenstrydig met Skrif en belydenis moet verwerp; dat die Kerk skole moet oprig waar God se lof besing kan word; en dat die kerklike reglemente hersien en 'n Christelike kerktug in leer en lewe gehandhaaf moet word (Rullmann, $1925: 2.425,426$ ).

Die reaksie van die Sinode op hierdie beswaarskrif was uiters teleurstellend. Die adressante is spottend die sewe Haagse wyses genoem. Maar dit het hulle nie ontmoedig nie. $\mathrm{n} 1843$ rig hulle 'n adres aan "de Hervormde Gemeente in Nederland" om die kerkvolk bewus te maak van hulle roeping. Tot sy dood in 1876 (tien jaar voor die Doleansie) het Groen van Prinsterer nooit opgehou om die vrysinnigheid in die Kerk aan te wys nie.

Groen van Prinsterer sou 'n kragtige medestryder vind in die 
persoon van dr. Abraham Kuyper wat eintlik die siel van die Doleansie word. Met De Heraut as kerklike blad het Kuyper die volk tot Reformasie opgeroep - "en het woord van Dr. Kuyper daarin was brandend; het sloeg meer in dan dat van Groen" (Rullmann 1925: 3.539). Sy Tractaat van de Reformatie der Kerken (1884), waarin hy pleit om 'n terugkeer na God se Woord en die suiwere belydenis van die kerk, was die stimulus tot die deurbraak van die Doleansie twee jaar later. "Kuyper was de theologische vertolker der herleefde gereformeerde gezindheid onder ons volk van de vorige eeuw als geen ander" (Honders s.j. 3.134).

Uit hierdie beknopte oorsig is dit duidelik dat die Besture van die Ned. Herv. Kerk, wat oorwegend in die hande van die vrysinniges was, self vir die brandstof gesorg het waarop die vuur van die Doleansie straks in hewigheid sou brand. By die veelheid van brandstof was daar veral twee voorvalle wat die Doleansie sterk aangehelp het.

\section{Die Vrije Universiteit}

Die eerste voorval was die stigting van die Vrije Universiteit op 20 Oktober 1880. In 1876 het daar 'n nuwe Wet op Hooger Onderw' $j s$ gekom, wat bepaal het dat Teologie voortaan nie meer op die universiteite doseer sou word nie, maar alleen Vergelykende studie van die godsdienste, waardeur die Christendom op een lyn met die heidense godsdienste gestel is. Die Sinode kon wel aan elke universiteit twee kerklike professore benoem, maar daarvoor het gewoon lik manne van die vrysinnige rigting in aanmerking gekom.

Dr. Kuyper e.a. was hiermee egter nie tevrede nie en het in 1880 die "Vrije Universiteit op Gereformeerde Grondslag" in Amsterdam opgerig. Hierdie Universiteit sou 'n bolwerk vir die Gereformeerde waarheid word en ook op ons land groot invloed uitoefen. Aangesien studente van die Vrije Universiteit nie as predikante in die Hervormde Kerk sou toegelaat word nie, moes dit tot 'n botsing lei.

Toe die eerste afgestudeerde kandidaat J. H. Houtzagers deur die kerkraad van Kootwijk beroep is, is die hele kerkraad geskors. Hierop het die gemeente die volgende dag die sinodale juk afgewerp en hulle opnuut gekonstitueer onder die kerkordening van Dordrecht (1886).

\section{Amsterdam}

Die tweede voorval wat direk aanleiding tot die Doleansie gegee het, was die kerklike stryd in Amsterdam. Toe die Sinode in 1883 die ondertekeningsformulier vir proponente so verander dat predikante hulleself slegs verbind "om die belange van die Godsryk te bevorder, terwyl hulle vroeër die kerkleer "in wese en hoofsaak moes handhaaf" (S. du Toit, 1970:137), het die gemeente van Amsterdam 'n vergadering van regsinnige kerkraadslede uit verskillende gemeentes bymekaar geroep en besluit dat niemand as predikant toegelaat sou word wat nie met die Belydenisskrifte instem nie. Verder is op hierdie vergadering te kenne gegee dat met dio organisasie in 1816 gebreek moet word wanneer dit die Gereformeerdes verhinder om op kerklike gebied hul beginsels uit te lewe. 
In 1886 is dit weereens Amsterdam wat die kerklike stryd ontketen. Die kerkraad het nl. geweier om attestasies aan katkisante van vrysinnige predikante te gee. Verder was daar 'n kwessie omtrent die beheer van kerklike goedere. Tagtig kerkraadslede het ten gunste van 'n voorstel gestem waarvolgens by 'n moontlike botsing die sinodale organisasie nie erken sal word nie. Op 4 Januaric 1886 word die 80 ouderlinge geskors. Toe al die geskorstes (op 5 na) op 1 Julie 1886 uit hulle amp ontslaan word en die Sinode hierdie vonnis op 1 Desember 1886 bekragtig, was die afskeiding 'n voldonge feit.

Op die 16de Desember 1886 word te Amsterdam 'n dolerende kerk gestig (dolerend beteken klagend, wat aandui dat hulle dit onbillik gevind het dat in talle hofsake die kerklike besittings hulle ontneem is). In Januarie $1887 \mathrm{kom}$ almal bymekaar wat die Sinodale hiërargie wou afwerp en die koningskap van Jesus in sy Kerk wil eer (Honders, 8.44). So kom die Nederduits Gereformeerde Kerk dolerend tot stand. In 1892 vind 'n vereniging met die kerke van die Afskeiding van 1834 plaas onder die naam: De Gereformeerde Kerken van Nederland.

\section{Die Vrije Universiteit nader beskou}

Die totstandkoming van die Vrije Universiteit was 'n magtige bolwerk vir die Gereformeerde waarheid en 'n magtige vesting van die Doleansie. Die lewensbeginsel van die Universiteit was: die volstreke onderwerping in elke lewenskring aan die Woord van God. Aanvanklik was daar net drie fakulteite nl. vir teologie, regte en lettere. Die vurige begeerte was egter dat die hele huis van die wetenskap- en nie slegs enkele kamers in daardie huis nie - gebou moet word op die fondament van God se Woord. Met die verloop van die jare is hierdie begeerte vervul: in 1930 is die wis- en natuurkundige fakulteit ingestel, in 1948 die fakulteit sosiale en ekonomiese wetenskap en in 1950 die mediese fakulteit. (Smitskamp $1961: 6.539)$.

Die Vrije Universiteit moes, volgens die bedoeling van die oprigters, nie 'n wig indryf tussen Gereformeerdes nie, maar 'n verenigingspunt wees van alle Gereformeerdes. Dit moes hoog bo alle kerklike twis uitstaan. Ongelukkig het die skeur, wat die Doleansie in 1886 tussen die Gereformeerdes in die Hervormde kerk getrek het, ook die Universiteit sterk beïnvloed. Baie Hervormde kerkrade en lidmate het nie meer bydraes gegee nie. Die beswaar dat die Vrije Universiteit die universiteit van die Gereformecrde Kerken was, was nie waar nie. Die Vrije Universiteit wou by uitnemendheid "Nederlandsche Hoogeschool" wees, wou sy arms verder uitstrek "dan naar wie van Gereformeerden huize is" (Rullmann, 1930:129). Die feit dat hy dit nie altyd kon doen nie, was die skuld van die Hervormde Kerk self wat geen student van dié universiteit op hulle kansels wou toelaat nie.

Die Vrije Universiteit moes aanvanklik baie spot verduur omdat dit so afhanklik was van die gifte en penninge van "duisende kleine luyden". Wat die spotters wel vergeet het, was dat elke pen- 
ning gespreek het van liefde en entoesiasme vir 'n hoë ideaal. Tot en met 1947 het die inkomste van die Vrije Universiteit grootendeels uit vrywillige bydrae van belangstellendes bestaan. Vanaf 1948 het daar 'n subsidiereëling van die kant van die staat tot stand gekom wat nuwe studierigtings en groot bouprogramme moontlik gemaak het.

\section{Die huidige VU}

Hoe is dit vandag met die Vrije Universiteit gesteld? Reeds in 1912 het die stigter van dié universiteit teen die gevaar gewaarsku "dat Satan toegang zou krijgen tot het Universitaire erf, door het bij nacht verleggen van de rails voor den trein der wetenschappen, of door het wierook geuren naar onzen kant toe uit den kring, waar we principieël tegen in moeten" (Rullmann, 1930:202).

In 1928 kon prof. Dr. J. Ridderbos na waarheid nog getuig dat "de geest, die de eerste stichters onzer Vereeniging bezielde, om namelijk het volstrekte gezag van Gods Woord boven alles te stellen, nog de geest is, die de leidende organen van onze Vereeniging bezielt; dat zij den band aan het Woord onverzwakt wenschen te handhaven, en niet van zins zijn, eenige afwijking daarvan te gedoogen, onder welken schoonklinkenden naam deze zich ook moge aandienen" (Rullmann, 1930:203).

In 1979 skryf $\mathrm{K}$. Runia met dankbaarheid dat daar nog jongmense is wat geen kritiek op Skrif en belydenis het nie, maar stel ook onomwonde "dat er afgestudeerden komen... van de VU... die vreemde leringen verkondigen" (Aanhalings uit Reformatorisch Opinieblad, KOERS, 26.1.1979). Oor die toestand in 1979 skryf Spoelstra die volgende: "Nou, in 1979 , leef die VU heerlik van ruim subsidies van die Nederlandse welvaartstaat. Die VU is na 100 jaar die grootste historiese leuen, gestalte van volkome ommekeer op gereformeerde erf. Teenoor die antitese van weleer verklaar hy hom vandag solidêr met die wêreld. Teenoor die beroep op die Konfessie is die minagting daarvoor skering en inslag". En dan die vraag vol versugting: "Gaan die eeufees van die VU 'n bekering in hart en lewe veroorsaak - of gaan die heersende gees binne die GKN voort rol op die toer van ekumenisme, maatskappy-kritiek, sosialisme, politieke evangelie en in die koor saam met Marx bly sing?" (Spoelstra $1979: 2$ ).

\section{Doleansie en die PU vir CHO}

Toe die Vrije Universiteit op 20 Oktober 1880 tot stand gekom het, is "een gevoelvol woord gesproken namens de stamverwante broeders in Zuid-Afrika door den heer Lion Cachet" (Rullmann, 1930 : 217). Die totstandkoming van 'n Christelike Universiteit in die stamland was vir die Gereformeerdes in Suid-Afrika só belangrik dat groete nie alleen oorgebring moes word nie, maar dat studente daar ook moes gaan studeer. Ons vra u aandag vir twee studente wat - deur die genade van die Here - nie alleen 'n sieraad vir die Vrije Universiteit was nie maar ook vir die kerk, van die Here, die onderwys, die PU vir CHO en vir Suid-Afrika nl. J. D. du Toit en F. Postma. 
Van jongsaf was J. D. du Toit besiel met die gedagte van Christelike onderwys en Christelike wetenskap. Omdat hy verbonde was aan die Teologiese Skool te Burgersdorp (met sy literariese department) wat met die Bybel as grondslag die wetenskap beoefen het, was dit sy vurige begeerte om aan 'n universiteit te studeer wat voor die Woord van die Here gebuig het (d'Assonville, 1977:41). Hier aan die Universiteit is sy denkwyse sterk beïnvloed deur die Doleansie-rigting. Kuyper het hom geleer dat godsdiens en nasionaliteit een is, dat Christus Koning is op al die terreine van die lewe en hierdie onderrig sou hy in sy hele lewe nie vergeet nie. (S. du Toit, $1959: 50$ ).

Skaars was du Toit terug in Suid-Afrika of hy begin hom beywer vir Christelik- nasionale onderwys. Hy sien 'n merkwaardige ooreenkoms in die Nederlandse en Suid-Afrikaanse skoolstryd. Die 1857-onderwyswet in Nederland maak slegs melding van Christelike deugde in die laerskole - en dit herinner hom aan die Smutswet van 1907, wat destyds vir mense in Suid-Afrika onaanvaarbaar was aangesien dit alle dogma uit die skool wou ban. Met hierdie bepaling lyk die wet volgens du Toit op die van die Franse Rewolusie periode (van der Walt, $1986: 11$ ).

In sy argumente teen die neutrale volkskool sluit du Toit hom telkens aan by A. Kuyper en J. Woltjer. Hy wys ook op Bilderdijk, Da Costa, Groen van Prinsterer, Elout van Soeterwoude en Kuyper as die Christelike "voorname" in die Nederlandse stryd teen die "ongelowige" beginsel van die naturalistiese opvoedkunde in die skoolwette van 1806, 1857 en 1878, manne wat in die geloof Christelike skole gestig het. In navolging van hulle voorbeeld pleit hy vir "vrye, Afrikaanse, Christelike Nasionale skole" (van der Walt, $1986: 11)$. Dit was J. D. du Toit se diepgewortelde oortuiging dat nòg die kerk nòg die volkslewe kan bloei as die skool nie tot sy reg kom nie.

Dr. du Toit het hom egter nie net vir Christelike Nasionale Onderwys beywer nie. Die ideaal van Christelike Hoër Onderwys het ook in sy hart gelewe. Saam met die latere prof. dr. F. Postma het hy reeds in Amsterdam gedroom van 'n Gereformeerde Vrye Universiteit in Suid-Afrika. Toe die Literariese Afdeling saam met die Teologiese Skool in 1905 na Potchefstroom verhuis en 'n swaar stryd deurgemaak het vanweë ingrypende veranderinge in die onderwyswette, het dr. du Toit 'n leeue-aandeel in hierdie stryd gehad.

Die ideaal van dr. du Toit was 'n Gereformeerde normaalskool. Hierdie ideaal is in 1920 verwesenlik toe die Potchefstroomse Universiteit vir Christelike Hoër Onderwys tot stand gckom het. In verband met die inkorporasie van die Literariese Afdeling by die Universiteit van Suid-Afrika het dr. du Toit 'n leidende rol gespeel. Op die Sinode van 1920 het sy advies die deurslag gegee. Ook in die stryd om die verwydering van die gewetensklousule het hy steeds op die voorpunt gestaan - 'n stryd wat by die selfstandigwording van die PU vir CHO met seën bekroon is toe dié Raad die reg ontvang het om die Christelike karakter van dié inrigting te bewaar.

Toe dr. J. D. du Toit in Amsterdam gedroom het van 'n Ge- 
reformeerde Vrye Universiteit in Suid-Afrika, was hy nie alleen nie. Prof. dr. F. Postma het saam met hom gedroom. Aan die Vrije Universiteit word hy in 1904 litterarum humaniorum candidatus en promoveer later, in 1914, in die filosofie en die lettere. Op 3 April 1904 word hy ingestel as professor litterarum aan die teologiese skool op Burgersdorp en verhuis saam met die skool in die volgende jaar na Potchefstroom. Toe die literariese departement van die teologiese skool 'n selfstandige universiteitskollege word, word prof. Postma rektor.

Prof. Postma se groot ideaal was die uitbouing van 'n inrigting vir Christelike hoër onderwys. Onvermoeid het hy hom daarvoor beywer: in 1916-18 vir afskeiding los van die teologiese skool; in 1919-21 vir inlywing by die Universiteit van Suid-Afrika; in 1921-33 vir die verkryging van die byskrif "vir C.H.O." by die naam van dié inrigting, en vir die versterking van die universiteitskollege op finansiële gebied; in 1921-50 vir volledige selfstandigheid as Potchefstroomse Universiteit vir Christelike Hoër Onderwys.

\section{Die PU vir CHO - 'n Evaluering}

Die beroemde natuurkundige Needham vergelyk die huis van die wetenskap wat in die $19 \mathrm{de}$ eeu neutraal geword het, met die huis waarvan die Here Jesus in Lukas 11:24-26 gespreek het. Volgens die Here Jesus het die onreine gees uit die mens uitgegaan, maar toe hy geen rus kon vind nie, het hy na die huis teruggegaan. Tot sy verbasing vind hy die huis leeg - om Needham se woorde te gebruik: hy het die huis neutraal gevind. Dit was vir hom die geleentheid om sewe ander geeste, slegter as hyself, uit te nooi om saam met hom in die huis te kom woon. Needham se afleiding is dit: as die Heilige Gees nie die huis van die wetenskap vervul nie, maar dit bly neutraal leeg staan, dan word die huis van die weten skap opnuut 'n spookhuis vol ander bose geeste (Verkuyl, $1978: 236$ ).

Watter pragtige beeld! Die Heilige Gees moet die huis van die wetenskap vervul. Nog meer: Hy moet die huis van die beoefenaars van die wetenskap vervul. As dit nie gebeur nie is die beoefening van die wetenskap in sy diepste wese ... neutraal!

Om die wetenskap in die lig van God se Woord te beoefen moet elke dosent en student onvoorwaardelik buig voor die gesag van God se Woord. Dit beteken dat hulle alles vir waaragtig moet hou wat God aan ons in sy Woord geopenbaar het (Heid. Kat. vr. 21). Verder moet hulle van die geloof uitgaan dat die vrees van die HERE die beginsel van die kennis is (Spr. 1. 7). Daarmee word nie bedoel dat die vrese van die HERE in die plek moet tree van wetenskaplike ondersoek nie, maar wel dat die eerbied vir God en sy gebooie (die liefde tot God en die naaste) altyd weer die uitgangspunt moet wees "en dat dus alles in het wetenschappelijk bedrijf getoetst moet worden aan de hoofdsom der Wet: de liefde tot God en de naaste" (Verkuyl, $1978: 238$ ). Dit beteken dat dosent en student die Bybel moet bestudeer, daaroor peins, in die prediking daarna luister, daaroor praat en daarby leef. Maar wie kan die Bybel verstaan as die Heilige Gees hom nie verlig nie? Daarom moet hulle ook 'n bid- 
dende lewe lei. Alleen in die weg van die gebed ontsluit die Heilige Gees vir my die Bybel as 'n lig vir my denke, as 'n gids wat my die weg wys deur die woude van wysgerige denke en soeke.

Christelike wetenskapsbeoefening moet verder op die waarheid berus. Dosent en student moet voor al die Gebooie buig - in besonder voor die negende om nie vals getuienis te gee nie. Die weteskap is nie 'n terrein waar die waarheid vanselfsprekend gedien word nie - dink aan die leuens van Darwin se evolusieteorie! Gedurig klink die vraag van Pilatus: "Wat is waarheid?" Om nie die waarheid op die terrein van die wetenskap te kruisig soos Pilatus Jesus gekruisig het nie, moet dosent en student in Jesus Christus glo wat gesê het: $\mathrm{Ek}$ is die Waarheid. Elkeen wat uit die waarheid is, luister na my stem" (Joh. 14.6, 18.37); en deur te luister na die Heilige Gees, wat die Waarheid is $(1$ Joh. 5.6) en wat met ons praat deur die Woord, wat die waarheid is (Joh. 17.17).

Omdat wetenskapsbeoefening so maklik tot hoogmoed kan lei, is dit nodig dat Christelike wetenskapsbeoefening altyd in 'n gees van nederigheid beoefen sal word. Daarom moet die wetenskaplike voortdurend sy onmag voor God bely met die woorde: "Nou ken ek ten dele" (1 Kor. 13.12). Baie Christenwetenskaplikes - Augustinus, Anselmus, Pascal, Newton - het die voorbeelde gestel deur van hulle studeerkamers en laboratoriums bidvertrekke te maak waarin hulle God ootmoedig gesmeek het om vergifnis vir teorieë, waarnemings, uitgangspunte en gedagtes wat nie met die waarheid ooreengestem het nie.

As hierdie gesindheid die hart van elke dosent en student beheers, sal ons oor die wetenskapsbeoefening van die Potchefstroomse Universiteit vir Christelike Hoër Onderwys waarlik kan skryf: "Want uit Hom en deur Hom en tot Hom is alle dinge".

En as dit nie gebeur nie? Dan word elkeen aan hierdie Universi teit opgeroep tot ware berou en bekering...'

\section{Werke waarna verwys word}

d'ASSONVILLE, V. E. 1986. Doleansie ' 86 - verset teen die modernisme (Referaat gelewer tydens herdenking van die Doleansie, PU vir CHO, 8.8. 1986).

d'ASSONVILLE, V. E. 1977. Totius - profeet van die Mooirivier. Kaapstad. Tafelberg-Uitgewers.

DU TOIT, S. 1970. Handleiding vir die studie van die kerkgeskiedenis. Potchefstroom, Pro-Rege-Pers.

DU TOIT, S. 1959. Jacob Daniël du Toit. In: Die Gereformeerde Kerk in SuidAfrika 1859-1959: 45-59.

HONDERS, H. J. 1964. De Gereformeerde Kerken na de Aufklärung. In: Geschiedenis van de Kerk, VIII. Kampen, Kok. 
RULlmANN, J. C. 1925. Haagsche Heeren (De zeven). In: Chr. Enc. II. 425426. Kampen, Kok.

HONDERS, H. J. S. J. De Gereformeerde Kerken na de Aufklärung. In: Geschiedenis der Kerk, III. 114-170. Kampen, Kok.

RULlmANN, J. C. 1925. Kuyper (Abraham). In: Chr. Enc. III. 538 - 548. Kampen, Kok.

RULlMANN, J. C. 1930. De Vrije Universiteit, Haar ontstaan en haar be staan. Amsterdam. Uitg. N.V. Dagblad Drukkerij De Standaard.

SMITSKAMP, H. 1961. Vrije Universiteit. In: Chr. Enc. VI 538 - 9. Kampen, Kok.

SPOELSTRA, B. 1979. Kan 'n eeufees die VU Amsterdam na eerste liefde bekeer? In: In die Skriflig. Jaargang $13 \mathrm{nr}, 49$, Maart 1979.

VAN DER WALT, J. L. 1986. Die Nederlandse skoolstryd, die Doleansie, en verbandhoudende onderwysgebeure in Suid-Afrika. (Referaat gelewer tydens herdenking van die Doleansie, PU vir CHO, 8.8.1986).

VERKUYL, J. 1978. Inleiding in de Evangelistiek) - In de wereld van wetenschap en techniek. Kampen, Kok. 